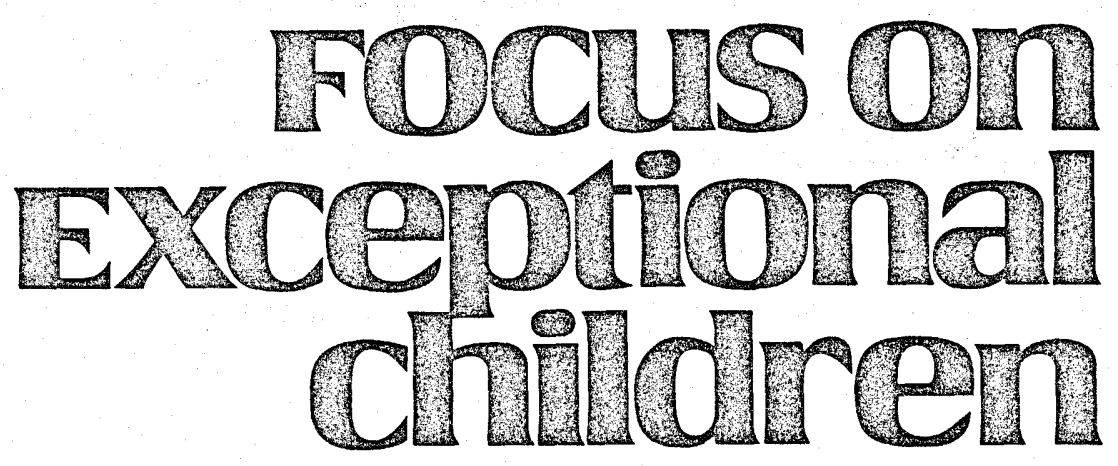

\title{
Cognitive Strategies for Teaching the Mildly Handicapped
}

Alan Sheinker, Jan M. Sheinker, and Linda J. Stevens

As recently as 2 years ago researchers were speculating about the applications of cognitive training to the classroom and warning that although this area of investigation had yielded promising results, the lack of careful research on actual applications was cause for caution in utilizing such approaches (Cavanaugh \& Perlmutter, 1982; Gerber, 1983; Kendall \& Mason, 1982). In her review of the research on cognitive behavior modification, Harris (1982) outlined the course that research has taken and the implications of that research for future application in the classroom. Since that review, significant progress has been made through research applying cognitive strategies to areas such as attention and memory, academic achievement, and strategic learning (Keogh, 1983).

For several reasons, the results of this classroom-related research are of interest to the practitioner working with midly handicapped students. First, teachers have long been aware of students' lack of success in applying what they were taught in the resource room to the regular classroom and in generalizing those skills from one task to another (Schumaker, Deshler, Alley, \& Warner, 1983). Some researchers believe that this inability to transfer learning results from an inherent passivity in learning disabled (LD) students' approach to academic tasks (Torgesen, 1979; Wong, 1982), and from lack of systematic planning for skills application activities to facilitate generalization (Meichenbaum, 1983). Several investigators advocate the inclusion of metacognitive training in the instructional program as a critical element of such planning (Brown \& Smiley, 1978; Meichenbaum, 1983; Sheinker, Sheinker, \& Stevens, 1983).

Second, researchers have noted that LD students appear to reach a learning plateau in high school that is equivalent to about a fourth or fifth grade achievement level (Deshler, Schumaker, Alley, Warner, \& Clark, 1982; Schumaker, Deshler, Alley, \& Warner, 1983). Interestingly, this achievement level is the point at which basic skills

Alan Sheinker is Director of Research and Development for Sweetwater County School District Number
One, Rock Springs, Wyoming. Jan Sheinker is a private educational consultant with background in direct
service, diagnostic testing, and teacher training in public schools. Linda Stevens is a doctoral candidate in
the Department of Educational Psychology's Psychology in the Schools Training Programs at the Univer-
sity of Minnesota and has provided technical assistance to federally-funded learning disabilities projects.

() Love Publishing Company, 1984. 
instruction generally ceases and students move on to apply those skills to inferential reading comprehension, math applications, expository writing, and extensive use of content textbooks for learning in science and social studies (Deshler, Warner, Schumaker, Alley, \& Clark, 1984). A new level of cognitive functioning is required for students to integrate and apply what they have learned. Academic achievement at this level requires that students know how to learn rather than just what to learn; strategic learning is essential to successful, efficient functioning in the regular classroom and to successful learning from content materials (Schumaker et al., 1983; Sheinker, Sheinker, \& Stevens, 1983). Although more research is needed, a number of studies completed over the past few years indicate that cognitive strategies instruction can be an effective tool to help students achieve beyond the basic skills level.

Finally, one goal that has been too seldom attained is the successful reintegration of special students in regular content classes (Deshler et al., 1982; Schumaker et al., 1983). Cognitive strategies training may hold the greatest

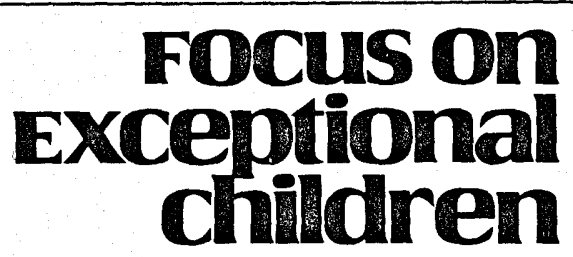

FOCUS ON EXCEPTIONAL CHILDREN (ISSNO0I5-5IIX) (USPS 203-360) is published monthly except June, July, and August as a service to teachers, special educators, curriculum specialists, administrators, and those concerned with the special education of exceptional children. This journal is abstracted and indexed in Exceptional Child Education Resources, and is also available in microform from Xerox University Microfilm, Ann Arbor, Michigan. Subscription rates, $\$ 18.00$ per year. Copyright $\odot$ 1984, Love Publishing Company. All rights reserved. Reproduction in whole or part without written permission is prohibited. Printed in the United States of America. Second class postage is paid at Denver, Colorado.

POSTMASTER: Send address changes to:

Love Publishing Company

Executive and Editorial Office

1777 South Bellaire Street

Denver, Colorado 80222

Telephone (303) 757-2579

EDITORIAL BOARD

Edward L. Meyen

University of Kansas
Glenn A. Vergason Georgia State University

Richard J. Whelan

University of Kansas Medical Center

Stanley F. Love

Publisher
Carolyn Acheson Senior Editor promise for spanning the distance between learning settings (Pearson, 1982). Many researchers (Brown \& Alford, 1984; Hallahan, Hall, Ianna, Kneedler, Lloyd, Loper, \& Reeve, 1983; Maier, 1980) have asserted that the results of their studies demonstrate that special students can master these strategies. Some (Hall, 1980; Harth, 1982) believe that although most special students possess cognitive and metacognitive skills, they require training in order to apply them appropriately. Gerber (1983) noted that LD children are not necessarily strategy deficient (connoting the absence of strategy use) but, rather, are strategy inefficient or strategy inflexible.

\section{AREAS OF RESEARCH IN COGNITIVE STRATEGIES INSTRUCTION}

Research in teaching cognitive strategies has addressed three amorphous and frequently overlapping concepts: cognitive behavior modification, comprehension monitoring, and metacognition. Different researchers frequently assign the same behaviors to two or more of these categories. To better communicate the nature and cognitive demands of the strategies to be discussed, definitions are suggested for each item.

- Cognitive behavior modification refers to the manipulation of covert thought processes to modify overt behavior (Hallahan \& Sapona, 1983). It involves a combination of behavior modification techniques and self-treatment methods such as self-monitoring, self-instruction, and self-evaluation (Hresko \& Reid, 1981).

- Comprehension monitoring involves the act of evaluating one's comprehension processes. Actions to regulate comprehension and resolve comprehension failure, included by some (Bos \& Filip, 1984) as part of comprehension monitoring, might more suitably be termed comprehension fostering activities (Palincsar \& Brown, in press). The combination of monitoring and regulation functions comprises metacomprehension (Fitzgerald, 1983).

- Metacognition involves knowing about and controlling one's own thinking and learning (Armbruster, Echols, \& Brown, 1983). Some theorists also refer to these processes as executive functioning (Forrest-Pressley \& Waller, 1984).

The difficulty in distinguishing among those areas is apparent in the above definitions. To recognize, however, 
that metacognition extends beyond the somewhat narrower limits of the other two categories, and in some sense subsumes them, may be important in practice.

\section{CAUTIONS}

The concerns of the early 1980s about application of cognitive strategies to the classroom are being addressed by researchers who have applied these techniques to instruction. With growing documentation of the effectiveness of these strategies and the pressing need for the academic progress these strategies may foster, practitioners are beginning to incorporate cognitive strategies into their arsenal of instructional tools. Some cautions should be considered in the implementation of these strategies:

- Don't abandon methods already in use that have proven effective for improving the academic performance of mildly handicapped students. For example, the cognitive strategies approach is not a substitute for direct instruction, which has been demonstrated to be effective in teaching basic reading and math skills (Adams, Carnine, \& Gersten, 1982; Carnine, 1983).

- Don't use cognitive strategies techniques as merely an add-on to what you are already doing (Palincsar \& Brown, in press). Cognitive strategies should be a distinct, well organized, integral part of the instructional sequence.

- Before attempting to implement cognitive strategy training in a classroom, be thoroughly versed in the aspects found by research to be effective (Peterson \& Swing, 1983). Haphazard use may result in unpredictable and possibly negative outcomes.

- Use cognitive teaching strategies appropriately; these strategies are not a substitute for basic skills instruction.

- Research suggests that cognitive strategy training may not be effective with students below the concrete operational stage of cognitive development (Nichol, Cohen, Meyers, \& Schleser, 1982). Many children do not attain this stage until third to fourth grade (Adams, Carnine, \& Gersten, 1982).

- Mastery of basic skills is prerequisite to acquisition and use of generalized cognitive strategies (Brown \& Alford, 1984; Lloyd, Saltzman, \& Kauffman, 1981). In most cases, students with achievement levels below mid-third to fourth grade will have difficulty generalizing the use of formally taught cognitive strategies (Brown \& Smiley, 1978).

- Choose applications of cognitive strategy instruction logically:

- Teach inferential comprehension as well as literal comprehension. Although direct instruction is effective in teaching literal skills, cognitive strategy instruction may be more effective in teaching inferential skills (Maier, 1980).

- Teach regrouping as well as basic facts in math. Preskills are necessary for successful cognitive strategy training (Lloyd, Saltzman, \& Kauffman, 1981). Direct instruction, drill, and precision teaching methods may be more efficient for basic facts (Carnine, 1983).

- Teach expository writing as well as mechanics and syntax (Harris \& Graham, in press). There is a variety of effective methods for teaching mechanics, but few validated techniques for teaching expository writing.

- Teach strategies for managing and recalling content materials as well as comprehending them. Distilling and organizing content for later recall are essential for successful studying, and require more than simply understanding what has been read (Armbruster, Echols, \& Brown, 1983).

With these cautions in mind, the current state of the art in classroom application of cognitive strategies is discussed here. By no means should this review be considered an exhaustive complilation of relevant research, or the applications discussed here be construed as the only appropriate ones for teaching cognitive strategies. Rather, we have selected recent studies that represent promising practices with documented effectiveness that appear to have immediate relevance for the practitioner. These include cognitive strategies instruction to enhance performance in memory and attention, academic learning (mathematics, written language, and reading comprehension), and studying content material. Future directions in cognitive strategy training and research are also discussed.

\section{GENERALIZATION}

A primary reason for the current interest in teaching cognitive strategies is the assertion of several researchers 
that strategy training may constitute a key ingredient in achieving generalization (Loper, 1980; Meichenbaum, 1983; Wong, in press). Many have theorized about the components of instructional practice necessary for ensuring generalization; yet, research on the accuracy of these hypotheses has been conducted only in the past few years. Guidelines for achieving generalization have been provided by Baer (1981) and by Meichenbaum (1983). Meichenbaum's recommendations are discussed below, documented by findings of recent research on achieving generalization.

\section{Analyze target behaviors.}

Know what you want to teach. The importance of careful goal setting and systematic task analysis in determining components of the desired behavior has long been documented (Carnine, 1983).

\section{Listen to the student.}

In designing appropriate interventions, one must determine the student's current use of strategies and detect individual differences that may inhibit strategic learning. Swanson (in press) notes that traditional assessment tools were not designed to evaluate children's specific processing strengths and weaknesses. Consequently, teachers must conduct systematic observations and collect formative data concerning baseline strategy use to design effective training programs.

\section{Select training tasks carefully.}

Training tasks teach the skills we intend to instill. If we wish students to make general use of a skill, we must design training tasks to encourage use of the strategies necessary for general application of that skill. Kendall (1981) found that impulsive 8- to 12-year-olds who received conceptual self-instruction training (using globally-worded directions that applied to a variety of problem situations) showed significantly better recall of training material on a one-year follow-up than students who received more task-specific self-instruction training.

Student characteristics should dictate the nature of the tasks. For example, teachers of handicapped students initially may have to provide mediating questions for tasks that provide a model of strategy use while encouraging students to develop their own mediating strategies. Harth (1982) described a study in which the experimenters observed students' poor problem-solving behaviors, identified their strategic deficiencies, and formulated methods of compensating for them through mediation of the task (e.g., the insertion of mediating questions).

\section{Collaborate.}

When generalizing skills to new situations and settings, students must be able to control application of their strategies. If training did not provide the student with experience in assuming responsibility for his/her own learning, the ability to appropriately apply those strategies may not develop. For example, Brown and Palincsar (1982) found that seventh grade poor comprehenders initially experienced significant difficulty in leading a dialogue concerning text segments-an activity that required them to generate questions and formulate hypotheses. Teachers initially found it necessary to model their own strategies, but as training progressed, students' ability to lead the discussion improved dramatically. Students continued to use the strategies 2 months after training was concluded.

Collaboration can also take the form of discovery learning. Schleser, Meyers, Cohen, and Thackwray (1983) found that an experimental group of third and fourth grade non-self-controlled children who were taught academic skills using a Socratic dialogue approach to discovery learning generalized those skills significantly better than did a control group or two selfinstruction groups trained in task-specific and general problem-solving skills.

\section{Train.}

Skill generalization calls for well-planned training based on mastery of prerequisite skills and incorporating metacognitive skills instruction. Neilans and Israel (1981) used direct and vicarious learning procedures to teach elementary school behaviorally handicapped students to monitor and evaluate their progress in math and reading; students observed the teacher self-goal-set, self-instruct, and self-evaluate after she/he described each skill. These students were better able to remain on task than students who were trained in a more conventional token economy system and also were able to generalize the self-regulation skills in their reading class. Palincsar and Brown (in press) found that intensive training of seventh grade poor comprehenders in the rationale, generality, range of utility, and self-regulation of comprehension monitoring activities resulted in sizable gains on laboratory and standardized comprehension tests, maintenance of those gains, and generalization of the strategies to both classroom comprehension tests and novel laboratory tasks. 


\section{Provide feedback.}

Students should receive explicit feedback to show that using the strategy improves performance. Ringel and Springer (1980) provided one treatment group of elementary students with feedback about how their use of a sorting strategy increased the number of pictures they could recall. These third grade students applied the strategy to a transfer task and recalled more than third graders who were merely taught how to implement the strategy.

\section{Generalize.}

Students need to be prompted to identify other opportunities to utilize strategies that are being learned. Palincsar and Brown (in press) found that explicitly training seventh grade poor comprehenders concerning the range of utility for a strategy facilitated its generaliization. Students were taught several comprehension strategies. Throughout instruction, the students were told that the strategies applied to other comprehension tasks and would improve their performance. The students later used the strategies in a social studies class although strategy use was not cued.

\section{Train in multiple settings.}

To foster generalization, training should occur in more than one setting or with more than one trainer or task. The ideal situation would be to provide all three, since different students require different combinations in order to generalize skills across settings. Schumaker et al. (1983) found that the opportunity to apply the strategies to a variety of regular classroom materials within the training setting enabled some LD adolescents to generalize strategy use outside the training setting; others required practice in other settings before generalization was evident.

\section{Prevent relapse.}

Safeguards are necessary to ensure that students do not regress to inefficient behaviors. Schumaker et al. (1983) accomplished relapse prevention by consulting with regular teachers in whose classes learning disabled adolescents were to apply the strategies taught in a resource room. Regular teachers were given the rationale for strategy use information about student performance before and after strategy training, cue cards listing the strategy steps to give the students as reminders, possible applications of the strategies in their classrooms, and methods for cuing the student to use the strategies in those situations. This approach resulted in significant improvement in regular class grades and greater teacher satisfaction with students' performance.

\section{Terminate training appropriately.}

Completion of training should depend upon student mastery of the strategy and demonstrated ability to apply the trained skill to a variety of tasks. Booster sessions should be provided as needed to prevent regression of strategy use to pre-training levels, and to quickly and effectively bring the skill back to post-training levels if regression occurs over time. Brown and Palincsar (1982) found that although seventh grade poor comprehenders maintained comprehension monitoring strategies at approximately a $60 \%$ level after training was concluded, reintroduction of strategy training produced an increase to a $90 \%$ performance level.

The evidence presented here strongly supports the effectiveness of systematic planning for generalization. Although this planning may initially require substantial effort, the results in improved prognosis for mildly handicapped students justify the expenditure of time and effort.

\section{MEMORY AND ATTENTION}

Considerable research has been conducted on the effects of cognitive strategy training on handicapped learners' performance in the areas of memory and attention. Unfortunately, most of the research on memory has been conducted in laboratory settings with relatively few applications to classroom instruction (Pressley, Levin, \& Bryant, 1983). Nevertheless, some of the hypotheses emerging from this research appear relevant to the selection and design of memory training tasks for mildly handicapped students. Although the volume of research on attention strategies is somewhat smaller, such research more frequently has been conducted in classroom settings, and thus has greater relevance for the practitioner.

Hagen and Barclay (1982) proposed four related periods of change in the strategic development of memory skills. The first period involves a "mediation deficiency" characterized by an inability to use a mnemonic strategy even when trained to do so. Newman and Hagen (1981) conducted a study in which primary and upper 
elementary LD students were trained in sorting and clustering strategies to assist free recall of 25 pictures. Although older students recalled more items after training, younger students did not improve, demonstrating a failure to spontaneously produce the trained strategy.

In the second period, students are capable of learning strategies but improvement in recall is minimal. Ringel and Springer (1980) found that training first graders in a sorting strategy did not improve recall on later sorting tasks. Students were able to use the strategy in a taskspecific manner but could not adequately apply the strategy to assist them on subsequent tasks.

The third period is one of production deficiency during which training can elicit an effective strategy. Newman and Hagen (1981) found that training in sorting improved the performance of upper elementary LD children in recalling a series of pictures. They hypothesized that these children had the sorting strategy in their repertoire but failed to apply it prior to training because they lacked awareness of the strategy's efficacy.

In the fourth period, students make appropriate spontaneous use of mnemonic strategies. In a study by Kurtz and Borkowski (1984), an experimental group of first and third graders who initially exhibited good metamemory skills and were taught rehearsal, clustering, and checking profited more from metacognitive skills training (selection, monitoring, and modification) than similarly trained children who initially demonstrated poorer metamemory skills. The children with better metamemory skills also were able to generalize the strategies more effectively to new tasks.

Despite the evidence cited here, some disagreement is apparent concerning the adequacy of the production deficiency hypothesis in explaining children's failures. Borkowski and Buchel (1983) have suggested that poor results may be attributed more to inadequate or inappropriate instruction than to the child's deficiency. Similarly, in their review of efforts to teach learning disabled students memorization skills, Gelzheiser, Solar, Shepherd, and Wozniak (1983) noted that most investigators have not taught integrated study plans with potential for generalization or trained skills to the point of automaticity. Instead, lower level, task-specific component skills have been taught. Those efforts, though often successful in meeting their limited goals, have not resulted in generalized application. As a result, this body of research does not provide a clear direction for determining either the content or sequence of memory strategy instruction in the classroom.

In contrast, recent research provides some excellent examples of methods to improve attention that can be used in the classroom. The relevance of these training techniques for the teacher of the mildly handicapped stems from evidence that such students may be unaware of factors necessary for maintaining attention. Loper, Hallahan, and Ianna (1982) noted that although they found a relationship between awareness of attention and achievement for normal 7- to 11-year-old children, the relationship did not hold for LD children of the same age except after successful academic intervention.

Results of a line of research conducted at the University of Virginia Learning Disabilities Research Institute (Hallahan et al., 1983; Hallahan \& Sapona, 1983) guided the development of procedures for designing classroom interventions to increase attention. Self-recording of on-task behavior by LD elementary school students with attentional problems has resulted in increased on-task behavior and, to a lesser degree, improved academic productivity. Although student monitoring of on-task behavior had to be cued initially, attending behavior was maintained even after self-recording and cuing were faded. Student self-assessment of on-task behavior was found to result in greater gains than teacher assessment, regardless of the accuracy of that self-assessment. These techniques were used successfully during both individual seatwork and group activities.

The self-monitoring procedure also was taught successfully to LD and non-LD students in a second grade classroom. Reinforcement for correct use of the procedure (e.g., recording their behavior each time the tone sounded) led to even higher levels of attention (Rooney, Hallahan, \& Lloyd, 1984). Similarly, when Rhode, Morgan, and Young (1983) trained behaviorally handicapped elementary school students in selfevaluation procedures in the resource room and then implemented a less intense procedure (which was subsequently faded) in the regular classroom, students generalized their improved behaviors to the new setting. As with other cognitive strategy training, prerequisite academic skill knowledge is necessary for effective modification of attending behaviors (Lloyd, Saltzman, \& Kauffman, 1981).

Several studies from the Virginia Institute (Hallahan, Lloyd, Kosiewicz, Kauffman, \& Graves, 1979; Hallahan, Marshall, \& Lloyd, 1981; Hallahan \& Sapona, 1983; Lloyd, Hallahan, Kosiewicz, \& Kneedler, 1982) yielded a consistent set of procedures for increasing attending behaviors in the classroom.

1. The teacher operationally defined attending and nonattending behaviors for the student. 
2. The teacher modeled the procedures to be followed by the student in self-assessing and self-recording on-task behaviors: A signal (supplied by a tape recorder or wrist counter) sounded at random intervals; when the signal sounded, the student asked him/herself, "Was I paying attention?"; the student recorded his/her evaluation of on-task behavior according to the definitions provided by the teacher.

3. The procedure was implemented. If necessary (as indicated by frequent inaccurate evaluations), the teacher intermittently verified the accuracy of the self-assessment.

4. Self-recording and cuing signals were faded as attending behavior became well established.

A complete description of the procedure is given in Improving Attention with Self-Monitoring: A Manual for Teachers (Hallahan. Lloyd, and Stoller, 1982).

\section{ACADEMIC LEARNING}

An early contribution to the application of cognitive behavior modification techniques to academic instruction was provided by Meichenbaum and Burland (1979). Elements of this approach have been incorporated into the work of several individual researchers and that of the University of Kansas and University of Virginia learning disabilities research institutes (Hallahan et al., 1983; Schumaker et al., 1983). This body of research has yielded considerable evidence concerning the efficacy of this approach, as well as specific guidelines for implementing such strategies in classroom settings.

Researchers at the University of Kansas (Deshler, Schumaker, Lenz, \& Ellis, 1984) found that not only could LD adolescents be taught task-specific strategies but that strategy learning resulted in improved classroom grades, regular teachers' perceptions of students' performance, and scores on district competency examinations. Ellis (1983) reported that LD adolescents who were taught an executive strategy for developing taskspecific strategies improved their performance in the regular classroom. Students were taught to assess setting and task demands, to generate their own task-specific strategies, to monitor strategy effectiveness, and to make necessary modifications, resulting in improved grades and teacher perceptions of product quality.

Research at the University of Virginia (Hallahan et al., 1983) has yielded some important findings concerning effective procedures for teaching cognitive strategies in classrooms. Investigators found that elementary LD students could be trained to apply attack strategies to a variety of academic tasks and that the training required little time when prerequisite skills were present. Students also were able to generalize those strategies to related tasks for which prerequisite skills had been learned. When prerequisite skills were the same for two new academic skills, mastery of attack strategies for one academic skill facilitated learning attack strategies for the second.

\section{Mathematics}

Researchers have devised other applications of cognitive strategy training. Genshaft (1982) used cognitive behavior modification with adolescent girls to reduce math anxiety. Although the students were not labeled handicapped, their math achievement was at least 1 year below their reading achievement. Students were taught to use covert self-instruction to talk themselves through math tasks they found anxiety-producing. Training resulted in both significant improvement on a standardized computation measure and more favorable attitudes toward math.

Leon and Pepe (1983) used self-instruction procedures to teach upper elementary LD and educable mentally handicapped students basic math computation skills. Self-instruction training was effective not only in teaching the computation skills but also in achieving generalization to similar skills that were taught directly. Students in the experimental group correctly completed 48 more modules covering skills not yet taught than students in the control group who received only skills training. Special education teachers provided individualized instruction using the following procedure:

1. Model. The teacher modeled overt self-instruction as she/he computed the math problem.

2. Reproduce the model. The teacher and student together computed a problem, with the student using self-instruction.

3. Self-instruct overtly. The student used outloud self-instruction to guide him/herself as she/he computed problems while the teacher assumed a monitoring role.

4. Fade self-instruction. The student whispered self-instruction statements as she/he computed problems while the teacher monitored the process. 
5. Self-instruct covertly. The student used covert (nonverbal) self-instruction as she/he computed problems.

Lloyd et al. (1981) formulated a more task-specific application of this procedure. In a study to determine whether attack strategy training could facilitate generalization of math computation skills, 8- and 9-year-old learning disabled boys were taught a four-step strategy to help them solve multiplication problems. For a given problem (e.g., $6 \times 2$ ), the student first pointed to the number in the problem by which she/ he could count ("I can count by $2 \mathrm{~s}$ "). Next the student made hashmarks for the other number $(/ / / / / /)$ and counted by the number to which she/ he was pointing (" $2,4,6,8,10,12$ "). Finally, the student wrote the last number (12) in the answer space. The instructional process included the same elements-teacher modeling, student reproduction of the model, and fading of overt self-instruction-proposed by Meichenbaum and Burland (1979), and used by Leon and Pepe (1983).

\section{Written Language}

Harth, Johns, Cloud, and Campbell (1981) reported a study in which cognitive strategies based on Feuerstein's theory of mediated learning experience were applied to written language instruction. Experimenters constructed activities to teach written language mechanics that included mediating directions and questions designed to focus sixth grade LD students' attention on the strategies necessary to select a correct response. Students were provided items requiring them to capitalize and punctuate sentences containing titles (e.g., "Michael Jackson wrote the song beat it."). Mediating directions and questions were provided (e.g., "A. First, I locate the title. B. What do I need to do-underline or use quotation marks? C. Which words should I capitalize?"). The skills acquired through use of this mediating strategy generalized to improved performance on traditional language arts assignments.

Investigators at the University of Kansas Institute for Research in Learning Disabilities (IRLD) developed four strategies that students used successfully to improve their ability to express information in reports, essays, tests, and assignments (Schumaker et al., 1983). LD students were taught a sentence writing strategy to construct four basic types of sentences, a paragraph writing strategy to organize and write coherent paragraphs, a theme writing strategy to organize and write an integrated multi- paragraph theme, and an error monitoring strategy to detect and correct errors in capitalization, punctuation, spelling, and overall appearance of written work.

Harris and Graham (in press) developed a strategy training approach to teach composition to upper elementary LD students using instructional procedures adapted from those of Meichenbaum (1977) and the University of Kansas IRLD (Schumaker et al., 1983). The stories students wrote after training received significantly higher quality ratings than those they wrote before training, and students maintained and generalized these gains over a 6-week period. The procedure consisted of six basic steps:

1. Teacher modeled and student practiced a taskspecific strategy. The teacher provided a definition and example of a specific language skill (e.g., use of action words). The student practiced applying the skill.

2. Current performance level and training goals were reviewed. Use of the targeted skill (e.g., use of action words) was charted, and the training goals and rationale for skill improvement were discussed.

3. Strategy steps and self-statements were introduced. A five-step strategy included looking at a stimulus picture and recording action words, generating a story idea to incorporate these action words, writing the story, evaluating the story and use of action words, and improving the story (e.g., adding more action words). The teacher modeled and the student practiced generating appropriate self-statements.

4. The teacher modeled the learning strategy and selfinstruction. Using a new stimulus picture, the teacher modeled four types of self-instruction: problem definition, planning, self-evaluation, and self-reinforcement. The student identified the four types and recorded examples of each.

5. Strategy steps and self-instruction types were memorized. The student memorized strategy steps and examples of the four self-instruction types.

6. Strategy steps and self-instruction were practiced. The student set a goal for the number of action words she/he would use, practiced the learning strategy and self-instruction with new stimulus pictures (initially using outloud thinking and fading to covert self-instruction), and charted the number of action words used.

A follow-up after several months indicated that students maintained knowledge of the task strategies and use of 
self-instruction over time and across settings, but strategy implementation was less consistent. The authors suggested that booster sessions should be provided following termination of training to ensure long-term maintenance of strategy use.

Cognitive strategy instruction also has been applied with some success to handwriting (Graham, 1983; Kosiewicz, Hallahan, Lloyd, \& Graves, 1982). Researchers using this approach trained students in selfinstruction and self-correction procedures. Booster sessions following termination of training were found to improve short-term performance (Kosiewicz et al., 1982).

\section{Reading Comprehension}

In recent years researchers have focused efforts increasingly on the area of comprehension monitoring. Comprehension monitoring refers to the metacognitive process involved in determining whether comprehension occurs and is influenced by person, task, and strategy variables. An individual's ability to evaluate his/her comprehension significantly affects his/her reading competency (Wagoner, 1983).

Although most of the research in this area has contrasted good and poor readers, a few recent studies have examined comprehension monitoring skills of learning disabled students. Bos and Filip (1984) found that LD seventh graders demonstrated a deficiency in comprehension monitoring when evaluating texts with specific inconsistencies, whereas average readers used comprehension monitoring skills to detect the text inconsistencies. When LD students were cued concerning the existence of an inconsistency, however, they were able to apply comprehension monitoring skills and to detect text confusions. Taylor and Williams (1983) found that LD students and nondisabled upper elementary students with similar reading achievement who were approximately 2 years younger performed comparably when asked to read paragraphs and to detect deviant sentences. A comparable group of LD students who read the passages silently while the examiner read them aloud, however, detected the deviant sentences with significantly greater accuracy.

Another study (Forrest-Pressley \& Waller, 1984) examined the relationships among knowledge of comprehension skills, monitoring, and performance on comprehension tasks of poor, average, and good readers in third and sixth grades. Younger and poor readers demonstrated a high rate of acceptance of incorrect sentences and were less able to predict their own comprehen- sion accuracy than older and better readers. Comprehension scores and use of comprehension strategies increased with age and reading achievement. Forrest-Pressley and Gillies (1983) suggested that younger and poor readers may not possess knowledge of the range of appropriate strategies and may not monitor their strategy use.

The relationship between strategy training, comprehension monitoring, and student performance on comprehension tasks was further examined by Short and Ryan (1984) in a study of fourth grade boys who were skilled and less-skilled readers. Implementation of a metacognitive intervention program consisting, in part, of story grammar training to improve comprehension monitoring resulted in dramatic increases in comprehension, as well as maintenance and generalization of strategy use.

Researchers at the University of Kansas IRLD developed several strategies that successfully increased the reading comprehension of high school LD students. The visual imagery strategy required the student to read a passage and form visual images representing the passage content. With the self-questioning strategy, the student formed questions about the passage during reading in order to maintain interest and improve recall (Clark, Deshler, Schumaker, Alley, \& Warner, 1984). In the paraphrasing strategy, the student paraphrased the main idea and important details of each paragraph. Another strategy, interpreting visual aids, helped the student gain information from charts, tables, pictures, diagrams, and maps (Schumaker et al., 1983).

Pearson and Gallagher (1983) developed a procedure that successfully taught elementary level poor readers to apply background knowledge and prediction strategies to comprehension tasks. In a number of studies with elementary school good, average, and poor readers (Gordon, 1980; Gordon \& Pearson, 1983; Hansen, 1981; Hansen \& Pearson, in press) using various forms of this procedure, trained students out-performed control group students on both standardized and informal inferential reading comprehension measures. The following procedure was used:

1. Prior to reading a story, students were given alternative story introductions. They were asked to relate the circumstances to their own experiences and predict what they thought might happen in two or three critical incidents from the story.

2. Students recorded their prior knowledge experiences and predictions separately and then integrated them on a third page. 
3. Students read the story and compared their predictions to story events.

4. Students were then helped to change their conceptions of the reading process by becoming aware of the "known" (experience) to "new" (story) principle by examining their comparisons. Hansen (1984) suggested that a questioning procedure may be used to help students discern these relationships.

From the results of their studies, Hansen and Pearson (in press) concluded that poor readers' inferential comprehension can be improved through strategy training.

In a more comprehensive procedure, Palincsar and Brown (in press) taught seventh grade poor readers summarizing, questioning, clarifying, and predicting strategies. Their results indicated that the most effective approach involved teaching prerequisite skills before attempting to teach the actual strategies, collaborating with the student in helping him/her to develop strategies, and making the general applicability of the strategies explicit to the student. The procedure included the following steps:

1. Locate the information. Students read a passage and answered 10 comprehension questions. The instructor praised correct answers and redirected the student to the appropriate portion of the passage to find responses for incorrect answers.

2. Define the strategies. Students were informed about the strategies they would use-summarizing, questioning, predicting, and clarifying.

3. Teach reciprocally. The instructor and students discussed the story to be read and predicted passage content, decided who would act as teacher (the student and instructor took turns in this role), and read a portion of the passage. The "teacher" asked questions, summarized, and offered predictions and clarifications for the next portion of the passage. The instructor used outloud thinking to model improved strategy use ("I might ask --," "Did this seem unclear?").

4. Explicate the need and means for generalization. Throughout the lessons, students were informed of the rationale for use of these strategies in silent reading and were given explanations of how paraphrasing text and anticipating questions that might be asked can be helpful in understanding what is read.

Informal measures of reading comprehension indicated the efficacy of these procedures. In addition, gains were maintained over a 2-month period following two booster sessions, and were generalized to comprehension tasks in a social studies classroom for a majority of the subjects.

\section{STUDYING CONTENT MATERIAL}

Research on the application of cognitive strategies to reading comprehension tasks has shown some promising results. Strategies that extend beyond those necessary for comprehension, however, are needed for meeting the goals of students' reading for study purposes in social studies, science, and other types of content (Baker \& Brown, 1980). Studying puts increased task demands on the student; in addition to simply understanding what was read, she/ he must be able to focus attention upon the ideas and relationships within the material that have to be remembered to obtain good test grades. Anderson and Armbruster (1982) described this strategic behavior as selection and retention of "high pay-off" ideas and relationships from textbook chapters.

According to recent research findings, these strategic behaviors appear to be lacking among poor readers. Carlson and Alley (1981) found that when compared to high-achieving high school students, LD high school students were deficient in note taking, monitoring writing errors, knowledge of test taking, scanning a textbook passage for information, and listening comprehension. Winograd (1983) concluded from his research on summarization with eighth graders that poor readers' difficulties with higher-order comprehension may relate to strategy deficits. Although poor readers were as aware as good readers of the purpose of summarizing, poor readers did not reflect that awareness through the information included in their summaries.

Moreover, the points of the passage that poor readers identified as important bore little relationship to the information contained in their summaries. Poor readers tended to draw almost half of their summary information from the first quarter of the passage; good readers drew one third from the first quarter, almost one fourth from the last quarter, and the remainder from the middle. This finding may relate to the tendency reported by Maria and MacGinitie (1982) for LD students to fix their attention on the first major topic discussed in a passage that related to their own prior knowledge. Lacking strategic behavior, these students may have difficulty attending to subsequent information.

Strategy instruction for mildly handicapped students may have a double benefit. Alvermann (1984) noted that the result of teaching strategies in content material is not 
only enhanced strategy use but increased content learning as well. In addition, Armbruster and Anderson (1981) observed that study strategies are taught most effectively through specific application to text materials. Instruction in "general" study strategies may be hindered by the need to adapt those general strategies to the specific characteristics of particular text. Students need to know more than the steps of the strategies; they need to know how, when, and why to apply them in specific situations.

Knowing how, when, and why to apply strategies requires the use of metacognitive skills. Alvermann and Ratekin (1982), however, found that even average seventh and eighth grade readers tended to use a limited range of passive strategies for studying. They speculated that this behavior may have resulted from a failure to recognize when other strategies were needed. Hare and Smith (1982) found that sixth and seventh grade students' accounts of their strategy use correlated significantly with their reading achievement. This finding suggests that the students' metacognitive awareness of their strategy use may relate to their ability to understand what they read. Forrest-Pressley and Gillies (1983) reported that older and better readers demonstrated greater metacognitive knowledge about comprehension fostering strategies, were better able to evaluate their success in comprehending, and were more likely to adapt strategies to meet task demands than younger and poorer readers.

Several attempts have been made to formulate effective study strategies instruction. Among the earliest of these efforts was the SQ3R method-survey, question, read, recite, review (Robinson, 1975). Although based on sound theoretical assumptions, this procedure has been used with disappointing results. In their reviews of the research on the effectiveness of this method, Graham (1982) and Johns and McNamara (1980) reported that SQ3R appeared to be no more effective than traditional study methods.

The University of Kansas IRLD developed several SQ3R strategies that successfully enhanced content learning by LD adolescents (Schumaker, Deshler, Alley, Warner, \& Denton, 1983). In the Multipass strategy, students went through a content chapter three times to familiarize themselves with the main ideas and organization of the passage, to gain specific information, and to test themselves on the chapter material. Other strategies included S.O.S.- an adaptation of Multipass in which selected portions of textbook chapter were marked and audiotaped for use by lower achieving LD students, and the listening-notetaking strategy, in which students were taught to listen for and identify cues in order to note and outline key words. A test preparation strategy, a testtaking strategy, and an assignment completion strategy were also developed.

Other study strategy approaches combine direct instruction and metacognition. Adams, Carnine, and Gersten (1982) developed a method for systematic instruction in study strategies. They used explicit definitions of the strategies, rationales for and teacher prompting of strategy use (subsequently faded), structured lessons requiring frequent student responses, and correction procedures, including methods for students to monitor their studying. A social studies text was used to teach fifth grade students the method, which was based, in part, on the SQ3R approach; instructors adhered to the restraints children normally encounter in the classroom (restrictions concerning timelines and writing in textbooks). The experimental group studied longer and performed significantly better than two comparison groups on an immediate short-answer test and maintained performance on a delayed test despite studying for a significantly shorter time.

Sheinker, Sheinker, and Stevens (1983) described another method that organizes study strategies instruction into a sequence consisting of skimming, summarizing, note taking, and outlining and uses regular content textbooks for training materials. The procedure, which has been used with LD (in groups of five to seven) and regular students (entire classrooms) in grades four through twelve, involved an initial use of direct instruction methods followed by training in metacognitive skills through discussion of rationales, use of questioning and outloud thinking techniques, and fostering of selfevaluative process. The following procedures (Sheinker \& Sheinker, 1982a) were used.

1. Determine current performance level. Before beginning instruction in each of the four strategies, the group was directed to read a textbook passage and execute the strategy (e.g., summarizing). Students graded their product by comparing it to the teacher's example.

2. Teach the skill. The teacher defined the strategy, introduced the strategy steps, and presented a rationale for each step. Students read a second textbook passage and independently executed the strategy.

3. Model strategy use through collaboration. With the teacher acting as facilitator, the group followed the strategy steps (brainstorming key points, combining related items, eliminating less important infor- 
mation, and rechecking). The teacher fostered self-evaluation of student contributions through a questioning procedure (e.g., "Why did you make that choice?" "How did you arrive at that conclusion?")

After students had made their contributions, the teacher modeled her/his own strategies through an outloud thinking process (e.g., "At first, I thought the main point was rising interest rates, but as I read further, I noticed that more space was devoted to discussing inflation. So I decided that the interest rates demonstrated only one aspect of inflation. What do you think?"). Students gradually assumed a more active role in the discussions, questioning and challenging each other to explain choices, thus stimulating further self-evaluation. In addition, students began to offer explanations for their choices without teacher questioning.

4. Explicate the need for and means of generalization. The teacher explained how the strategy (e.g., summarizing) helped students efficiently extract information from the textbook passage and that the strategy could be used with most textbooks (e.g., "Now that we have combined related key points into fewer sentences, we have fewer units of information to study and remember. Most textbook passages include discussions of points that can be combined to reduce the number of items to be studied").

5. Apply the strategies to a variety of materials. After the group mastered the strategy using the same textbook, students selected other texts and practiced the strategy individually. The teacher monitored progress and facilitated strategy use through the questioning techniques described earlier.

6. Monitor student progress and promote mastery. The teacher monitored performance by examining daily progress charts kept by each student. When students reached the mastery criterion (e.g., $80 \%$ accuracy of summary statements as compared to the group summary), the group moved to the next stage of instruction (individual practice or the next strategy).

An experimental group of tenth and eleventh grade LD students trained in this procedure performed significantly better on a standardized reading text than a comparison group taught decoding and reading comprehension skills using direct instruction procedures in alternative materials (Sheinker \& Sheinker, 1982b). Students in the experimental group, who received no other reading instruction, were trained to use study strategies in their social studies and science texts.

\section{CONCLUSIONS}

The instructional methods described here provide the practitioner with validated procedures for teaching cognitive strategies to mildly handicapped students. Several issues related to classroom applications, however, require further research and explanation: appropriateness of group versus individual instruction, position of strategy training along the instructional continuum, and the role of such training in achieving generalization of skills taught in the resource room to regular classroom content materials.

Many of the investigations reviewed here were conducted with individual students and utilized singlesubject designs. Although Sheinker and Sheinker (1982b) worked originally with groups, a number of other investigators also have recently taught cognitive strategies to groups of from two to seven handicapped students (Deshler, Warner, Schumaker, Alley, \& Clark, 1984; Palinscar \& Brown, in press; Rooney, Hallahan, \& Lloyd, 1984). Group instruction may provide some important benefits resulting from student interaction. Pearson (1982) noted that group (particularly small group) instruction consistently has been associated with achievement gains and appears to be more effective than individualized seatwork-oriented instruction. Group interactions may produce higher rates of academic responding; those higher rates, in turn, increase academic productivity (Hallahan \& Sapona, 1983).

Cognitive strategy training should not be regarded as a panacea for the skill deficits of handicapped students. Monitoring skills such as planning, self-testing, and predicting, however, may account for substantial differences between LD and non-LD learners (Wong, in press) and also may apply to other midly handicapped students. Because cognitive strategy instruction may be an essential part of an instructional sequence directed toward reintegration of handicapped students into regular classrooms, more specific information about its relationship to other techniques and its position along an instructional continuum would clarify some important issues for practitioners. Once students have been taught basic skills for each academic area (word attack and literal comprehension in reading, basic facts for each operation in math, mechanics and usage in written language), cog- 
nitive strategies may be a necessary part of the generalized use of those skills to foster mastery of inferential comprehension, math regrouping and reasoning, and expository writing.

Cognitive strategy training also may be essential in the final stage of special instruction, which has as its objective the successful reintegration of the handicapped student into the regular classroom. This stage, in which metacognitive skill training may play a key role, requires even broader generalization of inferential comprehension and expository writing skills to the study and interpretation of content material. If future investigations continue to validate the effectiveness of cognitive strategy instruction, this technique may hold promise for mildly handicapped students who have been unable thus far to apply skills taught in the resource room to task demands in the regular classroom. If that promise is fulfilled, a vital component may be added to the instructional process for these students.

\section{REFERENCES}

Adams, A., Carnine, D., \& Gersten, R. (1982). Instructional strategies for studying content area texts in the intermediate grades. Reading Research Quarterly, 18(1), 27-55.

Alvermann, D.E. (1984). Helping the LD learner read in the content areas. Topics in Learning \& Learning Disabilities, 3(4), $41-51$.

Alvermann, D.E., \& Ratekin, N.H. (1982). Metacognitive knowledge about reading proficiency: Its relation to study strategies and task demands. Journal of Reading Behavior. 14(3), 231-241.

Anderson T.H., \& Armbruster, B.B. (1982). Reader and textstudying strategies. In W. Otto \& S. White (Eds.), Reading expository material (pp. 219-241). New York: Academic Press.

Armbruster, B.B. \& Anderson, T.H. (1981). Research synthesis on study skills. Educational Leadership. 39(2). 154-156.

Armbruster, B.B., Echols, C.H., \& Brown, A.L. (1983). The role of metacognition in reading to learn: $A$ developmental perspective (Reading Education Report No. 40). Champaign: University of Illinois at Urbana-Champaign, Center for the Study of Reading.

Baer, D.M. (1981). How to plan for generalization. Lawrence, KS: H \& W Enterprises.

Baker, L., \& Brown, A.L. (1980). Metacognitive skills and reading (Tech. Rep. No. 188). Champaign: University of Illinois at Urbana-Champaign, Center for the Study of Reading. (ERIC Document Reproduction Service No. 195 932)

Borkowski, J.G., \& Buchel, F.P. (1983). Learning and memory strategies in the mentally retarded. In M. Pressley \& J.R. Levin (Eds.), Cognitive strategy research: Psychological foundations (pp. 103-128). New York: Springer-Verlag.

Bos, C.S., \& Filip, D. (1984). Comprehension monitoring in learning disabled and average students. Journal of Learning Disabilities, 17(4), 229-233.

Brown, A.L., \& Palincsar, A.S. (1982). Inducing strategic learning from texts by means of informed, self-control training. Topics in Learning \& Learning Disabilities, 2(1), 1-17.

Brown, A.L., \& Smiley, S.S. (1978). The development of strategies for studying. Child Development, 49, 1076-1088.
Brown, R.T., \& Alford, N. (1984). Ameliorating attentional deficits and concomitant academic deficiencies in learning disabled children through cognitive training. Journal of Learning Disabilities, 17(1), 20-26.

Carlson, S.A., \& Alley, G.R. (1981). Performance and competence of learning disabled and high-achieving high school students on essential cognitive skills (Research Rep. No. 53). Lawrence, KS: University of Kansas, Institute for Research in Learning Disabilities.

Carnine, D. (1983). Direct instruction: In search of instructional solutions for educational problems. In Society for Learning Disabilities and Remedial Education (Ed.), Interdisciplinary voices in learning disabilities and remedial education (pp. 1-60). Austin, TX: Pro-Ed.

Cavanaugh, J.C., \& Perlmutter, M. (1982). Metamemory: A critical examination. Child Development, 53, 11-28.

Clark, F.L., Deshler, D.D., Schumaker, J.B., Alley, G.R., \& Warner, M.M. (1984). Visual imagery and self-questioning: Strategies to improve comprehension of written material. Journal of Learning Disabilities, I7) 75-149.

Deshler, D.D., Schumaker, , Alley, G.R., Warner, M.M., \& Clark, F.L. (1982). Le: $g$ disabilities in adolescent and young adult populations: search implications. Focus on Exceptional Children, 15(1), 1-12.

Deshler, D.D., Schumaker, J.B., Lenz, B.K., \& Ellis, E. (1984). Academic and cognitive interventions for LD adolescents: Part II. Journal of Learning Disabilities, 17(3), 170-179.

Deshler, D.D., Warner, M.M., Schumaker, J.B., Alley, G. R., \& Clark, F.L. (1984). The learning strategies intervention model: Key components and current status. In J.D. McKinney \& L. Feagans (Eds.), Current topics in learning disabilities. Norwood. NJ: Ablex, pp. 245-284.

Ellis, E.S. (1983). The effects of teaching learning disabled adolescents an executive strategy to facilitate self-generation of task specific' strategies. Unpublished doctoral dissertation, University of Kansas, Lawrence.

Fitzgerald, J. (1983). Helping readers gain self-control over reading comprehension. Reading Teacher, 37(3), 249-253.

Forrest-Pressley, D.L., \& Gillies, L.A. (1983). Children's flexible use of strategies during reading. In M. Pressley \& J.R. Levin (Eds.), Cognitive strategy research: Educational applications (pp. 133-146). New York: Springer-Verlag.

Forrest-Pressley, D.L., \& Waller, T.G. (1984). Knowledge and monitoring abilities of poor readers. Topics in Learning \& Learning Disabilities, 3(4), 73-79.

Gelzheiser, L.M., Solar, R.A., Shepherd, M.J., \& Wozniak, R.H. (1983). Teaching learning disabled children to memorize: A rationale for plans and practice. Journal of Learning Disabilities, 16(7), 421-425.

Genshaft, J.L. (1982). The use of cognitive behavior therapy for reducing math anxiety. School Psychology Review, II(1), 32-34.

Gerber, M.M. (1983). Learning disabilities and cognitive strategies: A case for training or constraining problem solving? Journal of Learning Disabilities, 16(5), 255-260.

Gordon, C.J. (1980). The effects of instruction in metacomprehension and inferencing on children's comprehension ahilities. Unpublished doctoral dissertation, University of Minnesota, Minneapolis.

Gordon, C.J., \& Pearson, P.D. (1983). The effects of instruction in metacomprehension and inferencing on children's comprehension abilities (Tech. Rep. No. 277). Champaign: University of Illinois at Urbana-Champaign, Center for the Study of Reading.

Graham. S. (1982). Comparing the SQ3R method with other study techniques for reading improvement. Reading Improvement. $19(1), 45-47$. 
Graham, S. (1983). The effect of self-instructional procedures on LD students' handwriting performance. Learning Disability Quarterly, $6(2), 231-234$.

Hagen, J.W., \& Barclay, C.R. (1982). The development of memory skills in children: Portraying learning disabilities in terms of strategy and knowledge deficiencies. In W.C. Cruickshank \& J.W. Lerner (Eds.). Coming of age: Vol. 3. The best of ACLD (pp. 127-141). Syracuse, NY: Syracuse University Press.

Hall, R.J. (1980). Cognitive behavior modification and informationprocessing skills of exceptional children. Exceptional Education Quarterly, I(1), 9-15.

Hallahan, D.P., Hall, R.J., Ianna, S.O., Kneedler, R.D., Lloyd. J.W., Loper, A.B., \& Reeve, R.E. (1983). Summary of research findings at the University of Virginia Learning Disabilities Research Institute. Exceptional Education Quarterly, 4(1), 95-114.

Hallahan, D.P., Lloyd, J., Kosiewicz, M.M., Kauffman, J.M., \& Graves, A.W. (1979). Self monitoring of attention as a treatment for a learning disabled boy's off-task behavior. Learning Disability Quarterly, 2(3), 24-32.

Hallahan, D.P., Lloyd, J.W., \& Stoller, L. (1982). Improving attention with self-monitoring: A manual for teachers. Charlottesville, VA: University of Virginia Learning Disabilities Research Institute.

Hallahan, D.P., Marshall, K.J., \& Lloyd, J.W. (1981). Self-recording during group instruction: Effects on attention to task. Learning Disability Quarterly, 4(4), 407-413.

Hallahan, D.P., \& Sapona, R. (1983). Self-monitoring of attention with learning-disabled children: Past research and current issues. Journal of Learning Disabilities, 16(10), 573-636.

Hansen, J. (1981). The effects of inference training and practice on young children's comprehension. Reading Research Quarterly, 16, $391-417$.

Hansen, J. (1984). the role of prior knowledge in content area learning. Topics in Learning \& Learning Disabilities, 3(4), 66-72.

Hansen, J., \& Pearson, P.D. (in press). An instructional study: Improving the inferential comprehension of fourth grade good and poor readers. Journal of Educational Psychology.

Hare, V.C., \& Smith, D.C. (1982). Reading to remember: Studies of metacognitive reading skills in elementary school-aged children. Journal of Educational Research, 75(3), 157-164.

Harris, K. (1982). Cognitive-behavior modification: Application with exceptional students. Focus on Exceptional Children, I5(2), 1-16.

Harris, K.R., \& Graham, S. (in press). Improving learning disabled students' composition skills: A self-control strategy training approach. Learning Disability Quarterly.

Harth, R. (1982). The Feuerstein perspective on the modification of cognitive performance. Focus on Exceptional Children, 15(3), 1-12.

Harth, R., Johns, R., Cloud, C., \& Campbell, C. (1981). Mediation: How it can improve problem solving skills. Academic Therapy, $17(2)$, 225-230.

Hresko, W.P., \& Reid, D.D. (1981). Five faces of cognition: Theoretical influences on approaches to learning disabilities. Learning Disability Quarterly, 4, 238-243.

Johns, J.L., \& McNamara, L.P. (1980). The SQ3R study technique: A forgotten research target. Journal of Reading, 23(8), 705-708.

Kendall, P.C. (1981). One-year follow-up of concrete versus conceptual cognitive-behavioral self-control training. Journal of Consulting \& Clinical Psychology, 49, 748-749.

Kendall, J.R., \& Mason, J.M. (1982). Metacognition from the historical context of teaching reading. Topics in Learning \& Learning Disabilities, 2(2), 82-89.

Koegh, B.K. (1983). A lesson from Gestalt psychology. Exceptional Education Quarterly, 4(1), 115-127.

Kosiewicz, M.M., Hallahan, D.P., Lloyd, J., \& Graves, A.W. (1982). Effects of self-instruction and self-correction procedures on handwriting performance. Learning Disability Quarterly, 5(1), 71-78.

Kurtz, B.E., \& Borkowski, J.G. (1984). Children's metacognition: Exploring relations among knowledge, process, and motivational variables. Journal of Experimental Child Psychology, 37(2), 335-354.

Leon, J.A., \& Pepe, H.J. (1983). Self-instructional training: Cognitive behavior modification for remediating arithmetic deficits. Exceptional Children, 50(1), 54-60.

Lloyd, J.W., Hallahan. D.P., Kosiewicz. M.M., \& Kneedler, R.D. (1982). Reactive effects of self-assessment and self-recording on attention to task and academic productivity. Learning Disability Quarterly, 5(3), 216-227.

Lloyd, J., Saltzman, N.J., \& Kauffman, J.M. (1981). Predictable generalization in academic learning as a result of preskills and strategy training. Learning Disability Quarterly, 4, 203-215.

Loper, A.B. (1980). Metacognitive development: Implications for cognitive training. Exceptional Education Quarterly, I(1), 1-8.

Loper, A.B., Hallahan, D.P., \& lanna, S.O. (1982). Meta-attention in learning disabled and normal students. Learning Disability Quaterly, 5(1), 29-36.

Maier, A.S. (1980). The effect of focusing on the cognitive processes of learning disabled children. Journal of Learning Disabilities, 13(3), 34-38.

Maria, K., \& MacGinitie, W.H. (1982). Reading comprehension disabilities: Knowledge structures and non-accommodating text processing strategies. Annals of Dyslexia, 32, 33-59.

Meichenbaum, D. (1977). Cognitive behavior: An integrative approach. New York: Plenum Press.

Meichenbaum, D. (1983). Teaching thinking: A cognitive-behavioral approach. In Society for Learning Disabilities and Remedial Education (Ed.), Interdisciplinary voices in learning disabilities and remedial education (pp. 127-150). Austin, TX: Pro-Ed.

Meichenbaum, D., \& Burland, S. (1979). Cognitive behavior modification with children. School Psychology Digest, 8(4), 426-433.

Neilans, T.H., \& Israel, A.C. (1981). Toward maintenance and generalization of behavior change: Teaching children self-regulation and self-instructional skills. Cognitive Therapy \& Research, 5(2), 189-195.

Newman, R.S., \& Hagen, J.W. (1981). Memory strategies in children with learning disabilities. Journal of Applied Developmental Psychology, I(4), 297-312.

Nichol, G., Cohen, R., Meyers, A., \& Schleser, R. (1982). Generalization of self-instruction training. Journal of Applied Developmental Psychology, 3(3), 205-215.

Palincsar, A.S., \& Brown, A.L. (1983). Reciprocal teaching of comprehension-fostering and monitoring activities. Cognition and Instruction.

Pearson, P.D. (1982). A context for instructional research on reading comprehension (Tech. Rep. No. 230). Champaign: University of Illinois at Urbana-Champaign, Center for the Study of Reading.

Pearson, P.D., \& Gallagher, M.C. (1983). The instruction of reading comprehension. Contemporary Educational Psychology, 8, 317-344.

Peterson, P.L., \& Swing, S.R. (1983). Problems in classroom implementation of cognitive strategy instruction. In M. Pressley \& J.R. Levin (Eds.), Cognitive strategy research: Educational applications (pp. 267-289). New York: Springer-Verlag.

Pressley, M., Levin, J.R., \& Bryant, S.L. (1983). Memory strategy instruction during adolescence: When is explicit instruction needed? In M. Pressley \& J.R. Levin (Eds.), Cognitive strategy research: Ps.'chological foundations (pp. 25-49). New York: Springer-Verlag.

Rhode, G., Morgan, D.P., \& Young, K.R. (1983). Generalization and maintenance of treatment gains of behaviorally handicapped students from resource rooms to regular classrooms using selfevaluation procedures. Journal of Applied Behavior Analysis, I6(2), 171-188.

Ringel, B.A., \& Springer, C.J. (1980). On knowing how well one is remembering: The persistence of strategy use during transfer. Journal of Experimental Child Psychology, 29, 322-333.

Robinson, H.A. (1975). Teaching reading and study strategies. Boston: Allyn \& Bacon.

Rooney, K.J.. Hallahan, D.P., \& Lloyd, J.W. (1984). Self-recording 
of attention by learning disabled students in the regular classroom. Journal of Learning Disabilities, 17(6), 360-364.

Schleser, R., Meyers, A.W., Cohen, R., \& Thackwray, D. (1983). Selfinstruction interventions with non-self-controlled children: Effects of discovery versus faded rehearsal. Journal of Consulting \& Clinical Psichologi, $5 l(6), 954-955$.

Schumaker, J.B., Deshler, D.D., Alley, G.R., \& Warner, M.M. (1983). Toward the development of an intervention model for learning disabled adolescents: The University of Kansas Institute. Exceptional Education Quarterly, 4(1), 45-74.

Schumaker, J.B., Deshler, D.D., Alley, G.R., Warner, M.M., \& Denton, P.H. (1982). Multipass: A learning strategy for improving reading comprehension. Learning Disability Quarterly, 5(3), 295-304

Sheinker, J., \& Sheinker, A. (1982a). Study strategies: A metacognitive approach. Rock Springs, WY: White Mountain Publishing Co.

Sheinker, J.. \& Sheinker, A. (1982b). [The effects of study strategies training on reading comprehension]. Unpublished raw data.

Sheinker, J., Sheinker, A., \& Stevens, L. (1983). Study strategies: $A$ metacognitive approach (teachers'/trainers' manual). Rock Springs, WY: White Mountain Publishing Co.

Short, E.J., \& Ryan, E.B. (1984). Metacognitive differences between skilled and less skilled readers: Remediating deficits through story grammar and attribution training. Journal of Educational PSychology', 76(2), 225-235.

Swanson, H.L. (in press). Process assessment of intelligence in learning disabled and mentally retarded children: A multidirectional model. Educational Psychologist.

Taylor, M.B., \& Williams, J.P. (1983). Comprehension of learningdisabled readers: Task and text variations. Journal of Educational Psychology, 75(4), 743-751.

Torgesen, J.K. (1979). Factors related to poor performance on memory tasks in reading disabled children. Learning Disability Quarterly. $2(3), 17-23$.

Wagoner. S.A. (1983). Comprehension monitoring. What it is and what we know about it. Reading Research Quarterly, 18(3), 328-346.

Winograd, P.N. (1983). Strategic difficulties in summarizing texts (Tech. Rep. No. 274). Champaign: University of Illinois at UrbanaChampaign, Center for the Study of Reading.

Wong, B.Y.L. (1982). Strategic behaviors in selecting retrieval cues in gifted, normal achieving and learning-disabled children. Journal of Learning Disabilities, 15(1), 33-37.

Wong, B.Y.L. (in press). Metacognition and learning disabilities. In T.G. Waller, D. Forrest, \& E. MacKinnon (Eds.), Metacognition, cognition, and human performance. New York: Academic Press.

\section{computer update}

\section{by Barbara Thompson, Jerry Chaffin and Bill Maxw'ell}

This new column focuses on microcomputer technology and special education. We invite and encourage you to submit questions or suggest topics regarding this rapidly developing and exciting area. We plan to touch base with programs engaged in ongoing research and development and to interview persons most closely involved with microcomputer state-of-the-art and share their comments with you. In this first column we raise topics that may stimulate you to write us and offer suggestions or questions for future columns.

\section{CURRENT ISSUES}

\section{Software Accessibility}

Environmental accessibility was, and still is, a vital issue. Access to microcomputer software programs for

\footnotetext{
Barbara Thompson is a faculty member and project director of a preservice grant for the Department of Special Education, University of Kansas, Lawrence. Jerry Chaffin is a Professor of Special Education at the University of Kansas. Bill Maxwell is a programmer for Educational Information Systems, an educational software firm with which all the authors are affiliated. If you would like to have more information or have specific questions on a topic, please let us know c/o Dr. Barbara Thompson, University of Kansas, Dept. of Special Education, Room 344, Haworth Hall, Lawrence, KS 66045.
}

severely physically handicapped and sensory impaired populations is also a critical accessibility issue. Many software programs have the potential to be effective teaching tools, means of expression, of sources of entertainment for these populations, but access to these programs is frequently prohibited because they lack the flexibility to interface with adaptive response modes. The programming requirements are relatively simple, and needed hardware adaptations are for the most part available.

Software developers and publishers must be made more aware of the need to create options in software that allow effective use by physically handicapped and sensory impaired populations. The expense of creating separate software for a relatively small population of potential users is really not necessary and probably not realistically possible for most commercial publishers. What is needed are an awareness and a commitment on their part to include key options in software developed for the general population of consumers so that handicapped users are not denied access.

\section{Instructionally Sound and Flexible Educational Software}

The instructional techniques and methods special educators use are generally pedagogically sound and effective for any instructional setting. Software features that would benefit mildly handicapped populations would also benefit students in regular education settings. In 


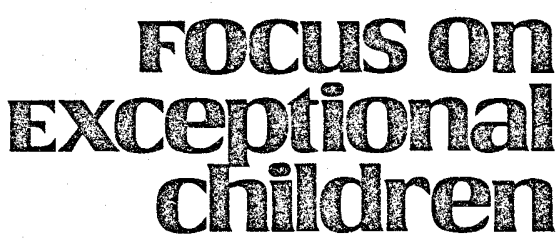

brief, these features are: (a) content options that represent a wide range of content difficulty levels, (b) clear and immediate feedback, (c) responsive action so that downtime within a program sequence is eliminated, (d) gradually increasing speed options toward a final speed level that ensures mastery (when appropriate for the content), (e) an option allowing teachers to enter selected content, (f) motivational formats, and (g) a two-or-more players option to maximize use and social interactions. In general, more programs that use the unique capabilities of microcomputer technology are needed. Too much software still functions like mechanical workbooks.

\section{Linkage/Integration}

Generalization is frequently difficult to obtain with handicapped students. Important skills and concepts practiced or learned on the computer must be effectively transferred to other settings and more traditional materials. In addition, the use of microcomputers in classrooms settings should be managed so that its powerful capabilities as an instructional tool are fully realized.

If both generalization from computer instruction and effective management of the computer are to be attained, methods and materials must be developed to enhance and facilitate these processes. This calls for more responsible development of software and the accompanying manuals and materials by publishers. Researchers, teacher trainers, and teachers also must make a concerted effort to explore and identify important strategies.

\section{Communication Networks}

Interestingly, the technology that many have feared would dehumanize education has required as well as offered a means for effective communication networks. By the time research studies about microcomputer technology have been published, the technology has frequently moved well beyond the variables investigated. To stay abreast of new software and hardware and their applications, administrators, teachers, support personnel, and parents need to be in contact with hardware and software developers, researchers, publishers, and each other. More effective methods of communicating new information should be explored, implemented, and compared.

\section{New Interdisciplinary Arrangements}

The advent of microcomputer technology has called for the addition of programmers and engineers to the team of support personnel needed to design and implement fully appropriate educational programs for handicapped students. Special educators and the traditional support disciplines must learn to more effectively communicate and plan with programmers and engineers who have the skills needed to actually create the software, hardware, and adaptive devices required for handicapped populations. Further, the creative role that programmers and engineers assume in these endeavors must be recognized and properly credited.

\section{FUTURE TRENDS}

\section{Linking of Video Disk and Microcomputer Technology}

The linking of video disk and microcomputer technology offers unlimited possibilities for creating realistic simulations that can be used for a wide range of training areas. Consider the potential for social skill training or vocational training when students can view a situation, make a decision, and actually see the results of their decision. Current work at Utah State University in this exciting new application of technology already offers possibilities for immediate application.

\section{Prosthetic Environments and Robotics}

The day is approaching when the debilitating aspects of many handicapping conditions can be eliminated. The independent management of home, school, and work environments by persons with a wide range of handicaps can be made possible through technology. In addition, robotics, previously confined to industry, may offer the potential for independent living and self-sufficiency for severely handicapped people who are currently completely dependent on able-bodied caretakers.

\section{Home Education}

As downloading of programs through cable TV networks becomes more and more of a reality, the availability of effective instructional programs to almost all homes is approaching rapidly. The IEP has already changed the nature of the relationship between parents and school personnel. The impact of microcomputer technology will, in all likelihood, be even more significant in altering this relationship. 